Edith Cowan University

Research Online

Research outputs 2014 to 2021

2019

Weight management among school-aged children and adolescents: A quantitative assessment in a Ghanaian municipality

Daniel Gyamfi

Christian Obirikorang

Emmanuel Acheampong

Edith Cowan University

Evans A. Asamoah

Bernard Berko Sampong

See next page for additional authors

Follow this and additional works at: https://ro.ecu.edu.au/ecuworkspost2013

Part of the Medicine and Health Sciences Commons

10.1186/s12887-019-1772-4

Gyamfi, D., Obirikorang, C., Acheampong, E., Asamoah, E. A., Sampong, B. B., Batu, E. N., \& Anto, E. O. (2019). Weight management among school-aged children and adolescents: A quantitative assessment in a Ghanaian municipality. BMC Pediatrics, 19.

Available here.

This Journal Article is posted at Research Online.

https://ro.ecu.edu.au/ecuworkspost2013/7009 


\section{Authors}

Daniel Gyamfi, Christian Obirikorang, Emmanuel Acheampong, Evans A. Asamoah, Bernard Berko Sampong, Emmanuella Nsenbah Batu, and Enoch O. Anto 


\title{
Weight management among school-aged children and adolescents: a quantitative assessment in a Ghanaian municipality
}

Daniel Gyamfi ${ }^{1}$, Christian Obirikorang ${ }^{2}$, Emmanuel Acheampong ${ }^{2,3^{*}}$ (D), Evans Adu Asamoah², Bernard Berko Sampong ${ }^{1}$, Emmanuella Nsenbah Batu ${ }^{2,4}$ and Enoch Odame Anto ${ }^{2,3}$

\begin{abstract}
Background: Childhood and adolescent overweight, obesity and underweight have become an issue of grave concern to both the developed and developing countries in context of global burden of non-communicable diseases. Unhealthy weight status is a significant public health issue for developing countries, of which Ghana is not excluded. This study evaluated the prevalence of overweight, obesity and underweight and its related factors among school-aged children and adolescents.
\end{abstract}

Methods: A total of 1004 participants were randomly selected from six schools. A structured questionnaire on demography and socioeconomic status of students' parents/guardians was completed by the selected students. Anthropometric parameters were measured, and body mass index (BMI) and waist-to-height ratio (WHtR) were calculated. BMI-forage z-scores were used to categorize anthropometric data of the children as underweight, normal, overweight or obese. A cut-off value of $>0.50$ was used to define obesity by WHtR.

Results: Overweight prevalence of $13.8 \%$ and 12.6 was observed among basic school and high school students respectively based on BMI classification. Obesity prevalence of $8.8 \%$ was found in basic school students and $8.9 \%$ among high school students. Underweight was observed in 114 (11.3\%) basic school students and 86 (8.6\%) high school students. There was a difference in sex prevalence in unhealthy weight-behaviours; with more girls being overweight $(19.4 \%$ vs $7.6 \%, p<0.001)$ and obese $(10.2 \%$ vs. $7.3 \%, p=0.177)$ compared to boys. High WHtR found in $10.5 \%$ of basic students and $5.0 \%$ of high school students, with a statistical difference. Overweight/obesity was significantly associated with taking snacks before bed among basic school students [aOR $=10.45(5.95-18)]$ and high school students [aOR $=10.23(5.95-18.37)]$ respectively. Watching TV $[\mathrm{aOR}=0.39(0.22-0.70)]$, sleeping during leisure periods $[\mathrm{aOR}=0.43(0.23-0.81)]$ and bicycling as a means of transport $[\mathrm{aOR}=0.37(0.19-0.72)]$ to school was protective of obesity among basic school students.

Conclusion: High prevalence of unhealthy weight-related behaviours was observed among school-aged children in the Bekwai Municipality. Snacking before bed was a major factor promoting obesity among school-aged children while leisure behaviours such as TV watching, and sleeping were protective of obesity. Therefore, it is recommended to promote and support healthy eating habits among school-aged children which are likely beneficial in reducing the risk of childhood unhealthy weight-related behaviours.

Keywords: Obesity, Overweight, Underweight, School-aged children, Adolescent

\footnotetext{
* Correspondence: emmanuelachea1990@yahoo.com

2Department of Molecular Medicine, School of Medical Science, Kwame

Nkrumah University of Science and Technology (KNUST), Kumasi, Ghana

${ }^{3}$ School of Medical and Health Sciences, Edith Cowan University, Joondalup,

Western Australia, Australia

Full list of author information is available at the end of the article
}

(C) The Author(s). 2019 Open Access This article is distributed under the terms of the Creative Commons Attribution 4.0 International License (http://creativecommons.org/licenses/by/4.0/), which permits unrestricted use, distribution, and reproduction in any medium, provided you give appropriate credit to the original author(s) and the source, provide a link to the Creative Commons license, and indicate if changes were made. The Creative Commons Public Domain Dedication waiver (http://creativecommons.org/publicdomain/zero/1.0/) applies to the data made available in this article, unless otherwise stated. 


\section{Background}

Ghana's economy is changing rapidly with an accelerated sustained economic growth which averages $8.0 \%$ per anum, and by the of 2019, Ghana's growth target is expected to improve to $9.7 \%$ by industries, $7.3 \%$ by the agricultural sector and $6.2 \%$ as the financial sector continues to recover from its recent challenges [1]. These developmental promises are only seen in a certain part of the country, which widens the health disparities between the rich and the poor, and further burden an already overwhelmed health care system in the country. Moreover, the under-going economic transition changes the food environment facilitating rapid nutrition transition to an energy-dense, but nutrient-poor diet in conjunction with a sedentary lifestyle that could potentially affect the weight status of children and adolescents [2]. In addition, food security continues to be an issue with about $5 \%$ of the Ghanaian population being food insecure, hence undernutrition in rural communities [3, 4].

The World Health Organization in 2018 estimated that over 340 million children and adolescents (5-17 years) worldwide are either overweight or obese [5]. In Sub-Saharan Africa, the weighted average of school-aged children being overweight/obesity and obesity between the periods of 1960 and 2013 was reported to be 10.6 and $2.5 \%$ respectively [6]. In Ghana alone childhood overweight/obesity ranges between 7.6 and $17.4 \%$ where female sex stands the greater risk [7, 8]. Moreover, in the Northern parts of Ghana, the records of underweight school-aged children are reported to be as high as $29.8 \%$ according to the reports of Morgre et al. [8] These statistics indicate overweight/obesity transition among school-aged children and adolescents in Ghana and Africa as a whole. Strong links have also been shown between obesity and cardiovascular diseases. Subsequently, obese and overweight children are at high risk of developing hypertension, angina pectoris, type 2 diabetes mellitus and dyslipidemia [9]. Additionally, underweight has been associated with conditions such as osteoporosis; skin, hair and teeth problems; as well as cardiovascular outcomes.

Data on childhood and adolescent underweight and overweight/obesity in Sub-Saharan Africa including Ghana is limited especially childhood obesity since it is less recognized in developing countries $[6,8]$. The 2014 annual composite reports in the Ashanti-Bekwai Municipality indicated that there was an increased incidence of non-communicable diseases (NCDs) mainly hypertension and diabetes mellitus from 1936 and 492 recorded in 2012 to 3618 and 1151 in 2014, respectively [10].

Despite positive advances made towards advertisements to prevent the intake of foods that is high in fats, sugars, and salt during television programmes aimed at children, limited action sits within the capabilities and responsibilities of health systems addressing such cases in the Bekwai municipality. Against this context, this study assessed the prevalence of underweight, overweight and obesity among school-aged within the Ashanti-Bekwai Municipality along with predisposing factors.

\section{Methods \\ Study design/site}

This was a cross-sectional study conducted among school-aged children and adolescents in 6 randomly selected schools within Ashanti-Bekwai Municipality. The Bekwai Municipal is one of the 30 administrative and political districts in the Ashanti Region of Ghana, located in the southern part of the region. It stretches over an area of $1937 \mathrm{~km}^{2}$ and lies within latitude $6^{\circ} 00^{\prime} \mathrm{N}$ and $6^{\circ} 30^{\prime} \mathrm{N}$ and longitudes $1^{\circ} 00 \mathrm{~W}$ and $1^{\circ} 35 \mathrm{~W}$. According the annual composite progress report of the Bekwai municipality, the estimated number of public and private school enrolment from primary up to senior high school in the year 2014 was 30,355 and 5540, respectively, featuring 191 schools [10]. The school attendance data for the population of Bekwai municipality is such that those attending basic and high school represent 76.7 and $23.3 \%$, respectively, from an estimated population of 36,322 active schooling population out of the total enrolled students [11].

\section{Study population and selection of students}

Using a multi-stage random sampling technique, students selected were within the age range of 5-17 years. To obtain a random distribution of the selected students from all classes, a proportionate random sample method was employed that included more students from larger classes.

\section{Sample size}

To obtain a representative sample size for the entire student's population (basic school and high school), at a confidence level of $95 \%$ and a margin of error of 0.036 , the formula below was used:

$$
n=\frac{N}{1+N(e)^{2}}
$$

Where $N=$ total basic and high school student population, $\mathrm{n}=$ estimated sample size, $\mathrm{e}=$ margin of error.

Also, to ensure a relative proportion of the students by level, the total student population was stratified according to basic and high school using the formula:

$$
\mathrm{ni}=\mathrm{n} \frac{\mathrm{Ni}}{\mathrm{N}}
$$

Where ni = sample size drawn from either primary or secondary schools, $\mathrm{Ni}=$ total population for either basic 
or high school, $\mathrm{N}=$ total student population, $\mathrm{n}=$ total estimated sample size. The sample size collected from both basic and high school were 702 and 302, respectively.

\section{Questionnaire administration}

The selected students were asked to complete a structured questionnaire developed based on the review of related journals. It consisted of sections on demography (age, sex, parents' occupation, and religion), eating habits (snacking status) and physical activity (means of transport and leisure activities). Parents or caretakers were made to answer the questionnaire for children below the age of 10 years. The ages of the selected students were determined using records available to the school. Children above 7 years were made to verbally confirm their age.

\section{Anthropometric measurements}

Anthropometric measurements of weight, height, and waist of the selected students were taken. All measurements were done at the school premises. Height was measured to the nearest $0.1 \mathrm{~cm}$ using a portable heightrod stadiometer. The weights of the students were also measured using a weighing scale with the reading taken to the nearest $0.1 \mathrm{~kg}$. Both measurements were taken on a flat surface with minimum clothing and without shoes. A good standing posture was maintained before each measurement was taken. A measurement of the hip (at the widest part of the buttocks) and waist (at the smaller circumference of the natural waist usually just above the belly button) of students were taken to the nearest centimetres using tape measures. Body mass index (BMI) and waist-to-height ratio (WHtR) was calculated as body weight divided by height squared $\left(\mathrm{kg} / \mathrm{m}^{2}\right)$ and the ratio of waist circumference $(\mathrm{cm})$ to height $(\mathrm{cm})$ respectively.

\section{Ethics approval and consent to participate}

Ethics approval [CHRPE/AP/170/15] was sought from the Committee on Human Research and Publication Ethics (CHRPE) at the Kwame Nkrumah University of Science and Technology, School of Medical Sciences. Approval was also sought from the Bekwai Municipality Education Office in collaboration with the management of the six participating schools. Definite criteria and the process for deciding what individual research information was given to children and their families were agreed upon by the management. Written consent was obtained from each participant prior to entry into the study. Parental consent was sought from the participant below 16 years of age.

\section{Statistical analysis}

Age and sex-specific prevalence of underweight, overweight and obesity were determined by body mass index for age percentiles using the criteria defined by the WHO cut-off points for school-aged children (WHO, 2014). According to the WHO cut-off points: overweight was $\geq 85$ th percentile; obesity, $>95$ th percentile; underweight, $<5$ th percentile; and normal, $>5$ th percentile to $<85$ th percentile. Obesity by WHtR was defined according to WHtR cut-off values of $>0.5$. Chi-square tests and cross-tabulations were used to compare and expressed categorical data as proportions (with Bonferroni correction for multiple comparisons. Logistic regression analysis adjusted for age was used to determine factors associated with underweight, overweight, obesity and higher WHtR prevalence with school as a fixed factor. All data were entered and managed in Microsoft Excel 2013 (Microsoft Corporation) and analysed using IBM Statistical Package for Social Scientists (SPSS) software version 22.0 (Chicago, USA). A level of $p<0.05$ was considered statistically significant.

\section{Results}

Female participants were the most presented from both basic and high schools (52.8 and 53.3\%) respectively. Majority of high school participants and basic schools' students were within the age bracket $10-15$ years $(71.2 \%$ vs $64.1 \%$ ). A higher percentage of both basic and high school students had parents with skilled occupations but differed significantly in terms of proportions $(58.5 \%$ vs $69.5 \%, p=0.001$ ). A considerable proportion of the students were from Christian homes in both basic and high school categories $(77.8 \%$ vs. $73.2 \%)$. The commonest means of transport used by students from both basic and high school was by car ( $60.5 \%$ vs. $55.3 \%)$. Watching television (TV) was the most activity performed by participants during their leisure periods (32.5 and 38.4\%, respectively) for basic and high school. More than half of students from both basic and high school participants took snacks before breakfast ( $58.7 \%$ vs 55.3 ) respectively Between lunch and supper snacking status was high among participants from high school (27.5\%) than basic school (20.4\%) (Table 1).

As shown in Fig. 1, underweight based BMI classification was found in $11.3 \%$ of basic school students and $8.6 \%$ high school students with no significant difference $(p=0.201)$. Overweight defined by BMI classification was higher among basic school students compared to high school students $(13.8 \%$ vs. $12.6 \%, p=0.608)$. Obesity identified based on BMI classification was found in equivalent proportions of basic and high schools' students $(8.8 \%$ vs. $8.9, p=0.959)$.

Using a cut-off of $>0.5$, higher WHtR was significantly observed in basic school students compared to high 
Table 1 General characteristics of the studied population stratified by school context

\begin{tabular}{|c|c|c|c|}
\hline \multirow[t]{2}{*}{ Variables } & \multicolumn{2}{|c|}{ School environment } & \multirow[t]{2}{*}{$P$-value } \\
\hline & $\begin{array}{l}\text { Basic School } \\
(n=702) \\
\mathrm{n}(\%)\end{array}$ & $\begin{array}{l}\text { High School }(n=302) \\
\text { n }(\%)\end{array}$ & \\
\hline Sex $x^{a}$ & & & 0.945 \\
\hline Male & $331(47.2)$ & $141(46.7)$ & \\
\hline Female & $371(52.8)$ & $161(53.3)$ & \\
\hline Age (years) ${ }^{b}$ & & & $<0.0001$ \\
\hline $5<x<10$ & $218(31.1)$ & 0 & \\
\hline $10-15$ & $450(64.1)$ & $215(71.2)$ & \\
\hline$>15$ & $34(4.8)$ & $87(28.8)$ & \\
\hline Occupation ${ }^{\text {b }}$ & & & 0.001 \\
\hline Unskilled & $291(41.5)$ & $92(30.5)$ & \\
\hline Skilled & $411(58.5)$ & $210(69.5)$ & \\
\hline Religion & & & 0.116 \\
\hline Christian & $546(77.8)$ & $221(73.2)$ & \\
\hline Islam & $156(22.2)$ & $81(26.8)$ & \\
\hline Means of transport ${ }^{b}$ & & & 0.209 \\
\hline Bicycle & $120(17.1)$ & 65 (21.5) & \\
\hline Car & $425(60.5)$ & $168(55.6)$ & \\
\hline Trekking & $157(22.4)$ & $69(22.8)$ & \\
\hline Leisure behaviours ${ }^{b}$ & & & 0.221 \\
\hline Football & $151(21.5)$ & $52(17.2)$ & \\
\hline Reading & $95(13.5)$ & $45(14.9)$ & \\
\hline TV watching & $228(32.5)$ & $116(38.4)$ & \\
\hline Sleeping & 147 (20.9) & $62(20.5)$ & \\
\hline Others & $81(11.5)$ & $27(8.9)$ & \\
\hline Snacking Status ${ }^{b}$ & & & 0.039 \\
\hline Before Bed & $147(20.9)$ & $52(17.2)$ & \\
\hline Before breakfast & $412(58.7)$ & $167(55.3)$ & \\
\hline Btn lunch and supper & $143(20.4)$ & $83(27.5)$ & \\
\hline
\end{tabular}

All values are presented as frequency and subset of school category proportions

${ }^{a}$ Fischer exact test

${ }^{\mathrm{b}}$ Chi-Square test, $P<0.05$ is considered stattistically significant

school students $(10.5 \%$ vs. $5.0 \% p=0.004)$. The prevalence of underweight by BMI classification was significantly higher among basic schoolboys compared to girls $(15.4 \%$ vs $7.5 \%, p$-value $=0.001)$. Also, underweight was prevalent in 8.5 and $8.7 \%$ of boys and girls respectively among high school students. The prevalence of overweight by BMI classification was significantly higher among basic schoolgirls compared to boys $(19.4 \%$ vs $7.6 \%, p$-value < 0.0001$)$. Overweight $(19.4 \%$ vs $7.6 \%)$ and obesity $(10.2 \%$ vs $7.3 \%)$ were prevalent among basic school females compared to males. However, among high school students, overweight (13.5\% vs $11.8 \%)$ and obesity (9.2\% vs $8.7 \%$ ) were more prevalent among males compared to females. Higher WHtR was prevalent in higher proportion among basic school boys (16.0\%) compared to basic school girls (5.7\%) (Table 2).

The proportion of underweight prevalent among students within the $5<\mathrm{x}<10$ age range was higher compared to students within the $10-15$ years and $>15$ years age bracket $(18.3 \%$ vs $9.0 \%$ vs $5.8 \%, p<0.0001)$. Also, higher WHtR was more prevalent among students within the age range $5<\mathrm{x}<10$ compared to students within the $>15$ years age bracket $(12.4 \%$ vs $4.8 \%)$. The prevalence of underweight was significantly higher among Muslims students compared to Christian students $(15.2 \%$ vs $9.0 \%, p=0.006)$. Statistically significance difference was observed for overweight and obesity categories according to students' with higher prevalence observed among students that take snacks before bed (42.7 and 23.1\%) compared to students that takes snacks before breakfast (4.7 and 7.9\%) and between lunch and supper (7.1 and 7.1\%) (Table 3).

Logistic regression analysis adjusted for age demonstrated that female sex was significantly associated with increased likelihood of overweight/obesity $(\mathrm{aOR}=2.16)$ but decreased the likelihood of being underweight $(\mathrm{aOR}=0.61)$ among basic school students. Taking snacks before bed was significantly associated with 10.45- and 10.23-times likelihood of obesity/underweight among basic school and high school students respectively. Football playing $(\mathrm{aOR}=0.47)$, $\mathrm{TV}$ watching $(\mathrm{aOR}=0.39)$ and sleeping $(\mathrm{aOR}=0.43)$ during leisure periods were associated with a decreased likelihood of overweight/obesity among basic school-aged students. Moreover, basic school students that traveled by means of bicycling was associated with less likelihood to be overweight/obese (aOR = $0.37)$ but increased odds of being lean $(\mathrm{aOR}=2.18)$. In addition, taking snacks before breakfast was significantly associated with less likelihood of underweight ( $\mathrm{aOR}=$ $0.39, p=0.001)$ and overweight/obese $(\mathrm{aOR}=0.54)$ among basic school students (Table 4).

Upon logistic regression analysis, female sex was associated with decreased odds of higher WHtR $(\mathrm{aOR}=0.32$, $p<0.0001)$ among basic school children. Moreover, basic school students with unskilled parents were associated with less likelihood of higher WHtR $(\mathrm{aOR}=0.57, p=$ 0.036) (Table 5).

\section{Discussion}

The results of this study indicated an overweight prevalence of 13.8 and $12.6 \%$, among basic school and high school students respectively. Also, an obesity prevalence of $8.8 \%$ among basic school students and $8.9 \%$ among high school students were observed. Additionally, obesity defined by WHtR $>0.05$ was prevalent in $10.5 \%$ of basic school students and $5.0 \%$ among high school students. Eating snacks before breakfast and being female 

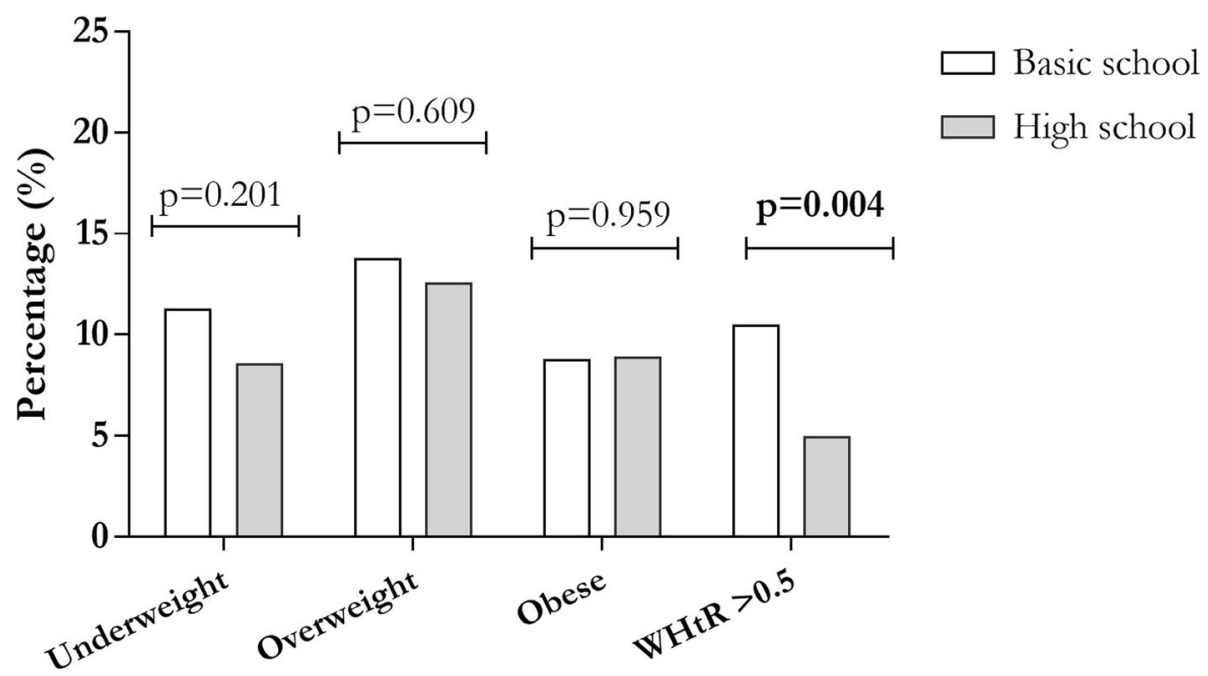

Weight-related behaviours

Fig. 1 Prevalence of unhealthy weight-related behaviours by school context

accounted for a significant prevalence of overweight/ obesity among school-aged children. Hitherto, watching $\mathrm{TV}$, sleeping, and football playing as leisure activities as well as bicycling as a means of transport to school was protective of overweight/obesity among basic schoolaged children. Moreover, a considerable prevalence of underweight (11.3\% among basic school students and $8.6 \%$ among high school students) was also observed, which was an indication of the co-existence of undernutrition and overnutrition, facilitating the transition of unhealthy weight-related behaviours in school-aged children within the Bekwai Municipality.

Overweight and obesity principally reflect positive energy balance; physical inactivity and poor dietary habits are two key modifiable factors that Overweight and obesity principally reflect positive energy balance; physical inactivity and poor dietary habits are two key modifiable factors that can influence this balance in a population. Aryeetey et al. [12], in a cross-sectional study conducted among school-aged children in urban Ghana, reported an overweight/obesity prevalence of $15 \%$ and indicated that low physical activity participation was associated with overweight and obesity among school-aged children which is partly consistent with findings in this present study. A similar cross-sectional study conducted in the Tamale Metropolis in Ghana, reported prevalence rates of 9.8 and $7.5 \%$ for overweight and obesity and indicated that obesity/overweight prevalence is associated with attending a private school, high level of parental education, playing computer/video games and eating food at the school canteen [13]. In the same year, [8] another study among school-aged children between 5 and 14 years age group in the Tamale metropolis reported an overweight/obesity prevalence of $17.4 \%$ which is in concordance to our present finding. We should underscore that childhood obesity is prominent in the Ghanaian population, therefore, the contextualization of obesity prevalence in Ghana requires a combination of factors such as dietary and physical activities that have a concurrent effect on obesity prevalence. Evidence from the literature indicates that increasing weight is the result of caloric imbalance and this is mediated by genetic, behavioral, and environmental factors driving the pathogenesis [14].

Table $2 \mathrm{BMI}$ and WHtR status of the study population stratified by school context

\begin{tabular}{|c|c|c|c|c|c|c|}
\hline \multirow{2}{*}{$\begin{array}{l}\text { Weight-related } \\
\text { behaviours }\end{array}$} & \multicolumn{3}{|l|}{ Basic school } & \multicolumn{3}{|c|}{ Secondary school } \\
\hline & Boys $(n=331)$ & Girls $(n=371)$ & $P$-value & Boys $(n=141)$ & Girls $(n=161)$ & $P$-value \\
\hline Underweight (\%) & $15.4 \%$ & $7.5 \%$ & 0.001 & $8.5 \%$ & $8.7 \%$ & 0.951 \\
\hline Healthy weight (\%) & $69.8 \%$ & $62.8 \%$ & 0.051 & $68.8 \%$ & $70.8 \%)$ & 0.665 \\
\hline Overweight (\%) & $7.6 \%$ & $19.4 \%$ & $<0.0001$ & $13.5 \%$ & $11.8 \%$ & 0.657 \\
\hline Obese (\%) & $7.3 \%$ & $10.2 \%$ & 0.177 & $9.2 \%$ & $8.7 \%$ & 0.879 \\
\hline WHtR > $0.5(\%)$ & $16.0 \%$ & $5.7 \%$ & $<0.0001$ & $2.8 \%$ & $6.8 \%$ & 0.110 \\
\hline
\end{tabular}

All values are presented as and compared using Chi-square test of trend, $P<0.05$ is considered stattistically significant 
Table 3 Prevalence of unhealthy weight-related behaviours by socio-demographic characteristics

\begin{tabular}{|c|c|c|c|c|}
\hline Variable & $\begin{array}{l}\text { Underweight } \\
(\%)\end{array}$ & $\begin{array}{l}\text { Overweight } \\
(\%)\end{array}$ & $\begin{array}{l}\text { Obesity } \\
(\%)\end{array}$ & $\begin{array}{l}\text { WHtR (>0.5) } \\
(\%)\end{array}$ \\
\hline \multicolumn{5}{|l|}{ Age (years) } \\
\hline $5<x<10$ & 18.3 & 8.7 & 9.6 & 12.4 \\
\hline $10-15$ & 9.0 & 13.8 & 7.7 & 7.6 \\
\hline$>15$ & 5.8 & 15.9 & 13.0 & 4.8 \\
\hline$P$-value & $<0.0001$ & 0.070 & 0.052 & 0.012 \\
\hline \multicolumn{5}{|l|}{ Occupation } \\
\hline Unskilled & 10.2 & 13.6 & 9.4 & 7.3 \\
\hline Skilled & 10.6 & 13.4 & 8.5 & 9.8 \\
\hline$P$-value & 0.841 & 0.928 & 0.621 & 0.212 \\
\hline \multicolumn{5}{|l|}{ Religion } \\
\hline Christian & 9.0 & 13.8 & 8.9 & 9.3 \\
\hline Islam & 15.2 & 12.2 & 8.9 & 7.6 \\
\hline$P$-value & 0.006 & 0.528 & 1.000 & 0.422 \\
\hline \multicolumn{5}{|l|}{ Means of transport } \\
\hline Bicycle & 13.5 & 9.2 & 5.4 & 11.1 \\
\hline Car & 9.9 & 14.3 & 9.3 & 7.8 \\
\hline Trekking & 9.3 & 14.6 & 10.6 & 9.7 \\
\hline$P$-value & 0.311 & 0.170 & 0.213 & 0.283 \\
\hline \multicolumn{5}{|l|}{ Leisure behaviours } \\
\hline Football & 11.8 & 15.3 & 7.4 & 14.3 \\
\hline Reading & 12.1 & 15.7 & 9.3 & 10.7 \\
\hline TV watching & 11.0 & 12.5 & 6.4 & 4.7 \\
\hline Sleeping & 8.6 & 11.0 & 9.6 & 8.6 \\
\hline Others & 7.4 & 14.8 & 17.6 & 10.2 \\
\hline$P$-value & 0.594 & 0.608 & 0.009 & 0.003 \\
\hline \multicolumn{5}{|l|}{ Snacking Status } \\
\hline Before Bed & 10.1 & 42.7 & 23.1 & 13.6 \\
\hline Before breakfast & 8.5 & 5.2 & 4.7 & 7.9 \\
\hline Between lunch and supper & 15.9 & 8.8 & 7.1 & 7.1 \\
\hline$P$-value & 0.017 & $<0.0001$ & $<0.0001$ & 0.029 \\
\hline
\end{tabular}

The evidence of childhood obesity as an emerging public health-related problem in the Bekwai Municipality is imminent [9]. Interestingly, the annual composite reports of the Bekwai municipality indicated that obesity prevalence among school-aged children was less than $1 \%$ [10]. Thus, the combined prevalence of overweight and obesity demonstrated in this present study is indeed indicative of increased future trends of childhood obesity coupled with attendant problems within the Municipality. In recent systematic review and meta-analysis by Muthuri et al. [6] reported a weighted average of overweight/obesity and obesity only to be 10.6 and $2.5 \%$ respectively, from 1960 to 2013 in studies reviewed from the entire Sub-Saharan African Zone. The results of our study are consistent with recent reports from several studies elsewhere in Africa and this highlights that overweight/obesity transition is evident among school-aged children in Sub Saharan Africa [7, 8, 15, 16].

Our findings showed a positive relationship between female sex and overweight /obesity, among basic school students but not high school students, which is consistent with previous findings [6-8]. A cross-sectional study conducted by Toriola et al. [17], reported no significant sex differences for BMI between boys and girls up to 13 years. However, the same study reported that increased age ( $>13$ years) was associated with significant sex differences for BMI.

In this study, basic school students represented a group whose peak ages range from 5 to 15 years compared to high school students who were older (10 to 
Table 4 Logistic regression analysis of factors associated with underweight, overweight and obesity among the students

\begin{tabular}{|c|c|c|c|c|}
\hline \multirow[t]{2}{*}{ Variable } & \multicolumn{2}{|l|}{ Basic School } & \multicolumn{2}{|l|}{ High School } \\
\hline & $\begin{array}{l}\text { Underweight } \\
\text { aOR (95\% Cl) }\end{array}$ & $\begin{array}{l}\text { Overweight/Obesity } \\
\text { aOR }(95 \% \mathrm{Cl})\end{array}$ & $\begin{array}{l}\text { Underweight } \\
\text { aOR }(95 \% \mathrm{Cl})\end{array}$ & $\begin{array}{l}\text { Overweight/Obesity } \\
\text { aOR ( } 95 \% \mathrm{Cl})\end{array}$ \\
\hline \multicolumn{5}{|l|}{ Sex } \\
\hline Female & $0.61(0.37-1.00)^{a}$ & $2.34(1.60-3.43)^{b}$ & $0.94(0.41-2.15)$ & $0.92(0.0 .53-1.61)$ \\
\hline Male & 1 & 1 & 1 & 1 \\
\hline \multicolumn{5}{|l|}{ Religion } \\
\hline Christian & $0.54(0.32-0.92)^{a}$ & $0.95(0.62-1.15)$ & $0.59(0.25-1.39)$ & $1.41(0.73-2.72)$ \\
\hline Muslim & 1 & 1 & 1 & 1 \\
\hline \multicolumn{5}{|l|}{ Occupation } \\
\hline Unskilled & $0.82(0.50-1.38)$ & $1.05(0.73-1.50)$ & $1.86(0.81-4.30)$ & $0.96(0.52-1.75)$ \\
\hline Skilled & 1 & 1 & 1 & 1 \\
\hline \multicolumn{5}{|l|}{ Means } \\
\hline Bicycle & $2.18(1.01-4.71)^{a}$ & $0.37(0.19-0.72)^{b}$ & $0.61(0.18-2.01)$ & $0.72(0.31-1.64)$ \\
\hline Car & $1.54(0.79-3.00)$ & $0.92(0.60-1.40)$ & $0.58(0.23-1.15)$ & $0.82(0.42-1.60)$ \\
\hline Trekking & 1 & 1 & 1 & 1 \\
\hline \multicolumn{5}{|l|}{ Leisure behaviours } \\
\hline Football & $2.24(0.87-6.41)$ & $0.47(0.26-0.87)^{a}$ & $0.82(0.13-5.45)$ & $0.84(0.29-2.48)$ \\
\hline Reading & $2.24(0.82-7.15)$ & $0.63(0.33-1.21)$ & $1.46(0.26-8.34)$ & $0.73(0.24-2.28)$ \\
\hline TV watching & $1.69(0.64-4.42)$ & $0.39(0.22-0.70)^{b}$ & $1.41(0.29-6.88)$ & $0.62(0.23-1.67)$ \\
\hline Sleeping & $1.27(0.45-3.56)$ & $0.43(0.23-0.81)^{b}$ & $0.83(0.14-4.95)$ & $0.84(0.29-2.40)$ \\
\hline Other activities & 1 & 1 & 1 & 1 \\
\hline \multicolumn{5}{|l|}{ Snacking } \\
\hline Before Bed & $1.55(0.73-3.30)$ & $10.45(5.95-18.37)^{b}$ & $1.72(0.46-6.40)$ & $10.23(4.42-23.68)^{b}$ \\
\hline Before Breakfast & $0.33(0.19-0.57)^{b}$ & $0.54(0.31-0.94)^{a}$ & $0.67(0.27-1.65)$ & $0.66(0.30-1.41)$ \\
\hline BLS & 1 & 1 & 1 & 1 \\
\hline
\end{tabular}

All values are presented as adjusted odds ratio (aOR) (95\% confidence interval), BLS-between lunch and supper, $\mathrm{Cl}$-confidence interval

${ }^{a}$ denotes significant level at 0.05 a-level

${ }^{\mathrm{b}}$ denotes significant at $0.01 \mathrm{a}$-level

greater than 15 years). The records of sex-specific obesity in our findings indicate that overweight and obesity were prevalent among 19.4 and $10.2 \%$ respectively among basic school-aged girls, compared to boys whose prevalence was 7.6 and $7.3 \%$ respectively. Comparatively, more boys were overweight and obese than girls in high schools. To some extent, sex dissimilarities with respect to the behavioral elements of overweight/obesity; calorie intake and physical activity, has been reported. The evidence existing presents findings in one aspect, that girls give more attention to healthy eating behaviours to meet nutritional recommendations than boys [18], whiles others also report that boys engage in vigorousintensity physical activities than girls [8]. Thus, sexspecific unhealthy weight-related behaviours are more specific to the study setting and existing practices of the study subjects.

From the discrete point view, childhood obesity is the result of an imbalance between the calories a child consumes as food and beverages and the calories a child uses to support normal growth and development, metabolism, and physical activity [19]. The disproportion between calories consumed and calories used can result from the influences and interactions of a number of factors, comprising genetic, behavioral, and environmental factors [14]. It has, therefore, become imperative that the interactions among these factors rather than a single factor should be critically considered in tackling the cause of underweight and obesity/overweight. Several studies have also reported that childhood overweight/ obesity is negatively associated with physical activity and positively associated with sedentary activities [20].

We found that football playing during leisure periods and bicycling as a means of transport to school, which represents vigorous-intensity exercise, was protective of overweight/obesity. Also, snacking status, especially, taking snacks before bed was associated with a significant prevalence of overweight (42.7\%) and obesity (23.1\%) among school-aged students. In a review report by Nuru and Mamang [21], children who eat a lot of snacks more 
Table 5 Logistic regression analysis of factors associated with high WHtR (>0.5) among study participants

\begin{tabular}{|c|c|c|c|c|}
\hline \multirow[b]{2}{*}{ Variable } & \multicolumn{2}{|l|}{ Basic school } & \multicolumn{2}{|l|}{ High Scholl } \\
\hline & $\mathrm{aOR}(95 \% \mathrm{Cl})$ & $P$-value & aOR $(95 \% \mathrm{Cl})$ & $P$-value \\
\hline \multicolumn{5}{|l|}{ Sex } \\
\hline Female & $0.32(0.19-0.54)$ & $<0.0001$ & $2.43(0.75-7.85)$ & 0.137 \\
\hline Male & 1 & & & \\
\hline \multicolumn{5}{|l|}{ Religion } \\
\hline Christian & $1.40(0.75-2.63)$ & 0.292 & $0.73(0.24-2.22)$ & 0.582 \\
\hline Muslim & 1 & & 1 & \\
\hline \multicolumn{5}{|l|}{ Occupation } \\
\hline Unskilled & $0.57(0.34-0.97)$ & 0.036 & $1.64(0.56-4.79)$ & 0.364 \\
\hline Skilled & 1 & & 1 & \\
\hline \multicolumn{5}{|l|}{ Means of Transport } \\
\hline Bicycle & $1.91(0.95-3.86)$ & 0.070 & 0.0 & - \\
\hline Car & $0.86(0.46-1.60)$ & 0.639 & $0.59(0.20-1.17)$ & 0.329 \\
\hline Trekking & 1 & & 1 & \\
\hline \multicolumn{5}{|l|}{ Leisure Activity } \\
\hline Football & $1.77(0.81-3.89)$ & 0.154 & 0.00 & - \\
\hline Reading & $0.79(0.30-2.06)$ & 0.623 & $3.97(0.45-34.95)$ & 0.214 \\
\hline TV watching & $0.41(0.17-1.01)$ & 0.052 & $0.95(0.10-8.86)$ & 0.962 \\
\hline Sleeping & $0.77(0.32-1.82)$ & 0.551 & $1.79(0.19-16.80)$ & 0.611 \\
\hline Other activities & 1 & & 1 & \\
\hline \multicolumn{5}{|l|}{ Snacking Status } \\
\hline Before Bed & $1.72(0.85-3.49)$ & 0.135 & 3.36 (0.59-19.06) & 0.171 \\
\hline Before Breakfast & $0.90(0.47-2.18)$ & 0.738 & $2.36(0.50-11.20)$ & 0.280 \\
\hline Before lunch and supper & 1 & & 1 & \\
\hline
\end{tabular}

All values are presented as adjusted odds ratio (aOR) (95\% confidence interval), Cl-confidence interval, $P<0.05$ is considered stattistically significant

frequently stand a higher risk of obesity, compared to those who eat snack without hungry feel. In a more recent study, Nisak et al., [22] reported that energy intake from snacking was found to be higher in obese children, which was attributed to the highest frequency of energydense food intakes such as flavored drinks and desserts. Eating a quick and nutritious snack just before bed can have nutritional benefits for school-aged students. However, if the resorts are flavored drinks and deserts, then the child has a higher risk of obesity. Although we did not assess the nutrition status of snacks in this study, the content of foods consumed by children before bed might explain the high prevalence rate of obesity with respect to snacking before bed.

Although watching TV and sleeping is a proxy measure for sedentary behaviours, we observed that TV watching and sleeping among basic school children during leisure periods was protective of obesity. Leisure periods denote times of quality experience or free time spent from basic routine activities. Several studies have reported, that sedentary leisure such as TV watching and sleeping is associated with high BMI levels among children and adolescents [23, 24], which is inconsistent with our findings. However, findings of Zimmerman and Bell [25], indicated that the content of TV shows is the major underlying factor for obesity prevalence among children. Thus, children that alternatively watch educational programs were not at risk of obesity compared to children who watched commercial programs. Zimmerman and Bell reported that most commercial programs are accompanied by junk food and sugar-sweetened beverages advertisement (similar to most commercial TV shows in Ghana) which influences the eating pattern of children, thus enhancing obesity prevalence. We, therefore, presumed that the content of TV watching rather than the practices among basic school children influenced the protective behaviour of TV watching for obesity in our study. Moreover, duration and timing of sleeping in alternating ways influence the risk of overweight or obesity during childhood [26]. Poor or lack of sleep among children has been reported to disrupt appetite-regulating hormones, thus causing weight gain [27, 28]. Thus, these 
reasons could affirm the protective role of sleeping for obesity prevalence among basic school children, found in our study.

Even though reports of this present study are comparable to other literature, the study design used in this present study was a cross-sectional which was not effective to establish a causal effect relationship between snacking status; leisure time activities; and childhood overweight/obesity. Moreover, the content of TV programs the children watched as well as the kind of food eating for snacks before bed was not assessed to effectively elaborate the effects on weight-related behaviours. It is, therefore, recommended that more elaborate research into the objective measurement of these exposures should be carried out to establish their true relationship with childhood overweight/obesity in the Ghanaian context. Again, constant monitoring of the nutritional status in school children should be considered by considering interventions such as breakfast and lunch clubs. Also, more physical education lessons should be included in the basic and high school curriculum.

\section{Conclusion}

A high prevalence of childhood overweight, obesity and underweight were found among school-aged children and adolescents. Snaking independently and significantly promotes obesity, overweight and underweight prevalence among school-aged children and adolescents whereas leisure behaviours such as TV watching, and sleeping were protective of obesity. Promoting and supporting healthy eating habits in this population is likely beneficial in reducing the risk of childhood unhealthy weight-related behaviours.

\section{Abbreviations}

BMI: Body mass index; WHtR: Waist-to-height Ratio

\section{Acknowledgments}

The Authors acknowledge the hard work of the school community teachers and tutors, Bekwai Municipality District Assembly and Education office, in their effortless contribution to the success of this study. We also acknowledge the Principal Investigator and his subordinates at the Department of Molecular Medicine, School of Medical Sciences, Kwame Nkrumah University of Science and Technology for their inputs on the design and accomplishment of the surveys.

\section{Authors' contributions}

DG was involved in data curation, formal analysis, methodology, software, supervision, validation, Writing - original draft, Writing - review \& editing; CO was involved in conceptualization, data curation, formal analysis, supervision, writing - original draft, writing - review \& editing; EA contributed in conceptualization, data curation, formal analysis, software, supervision, validation, writing - original draft, writing - review \& editing; EAA was involved in conceptualization, data curation, investigation, writing - original draft, writing - review \& editing; BBS was involved in data curation, investigation, methodology, writing - original draft, writing - review \& editing, ENB was involved in conceptualization, data curation, writing original draft, writing - review \& editing. EOA was involved in data curation, formal analysis, methodology and validation. All authors have read and approved the final manuscript for publication and agree to be accountable for all aspects of the work.
Funding

No funding was obtained for the study.

\section{Availability of data and materials}

The datasets used and analyzed during the study are available from the corresponding author on reasonable request.

\section{Ethics approval and consent to participate}

Ethics approval [CHRPE/AP/170/15] was sought from the Committee on Human Research and Publication Ethics (CHRPE) at the Kwame Nkrumah University of Science and Technology, School of Medical Sciences. Approval was also sought from the Bekwai Municipality Education Office in collaboration with the management of the six participating schools. Definite criteria and the process for deciding what individual research information was given to children and their families were agreed upon by the management. Written consent was obtained from each participant prior to entry into the study. Parental consent was sought from the participant below 16 years of age.

\section{Consent for publication}

Not applicable.

\section{Competing interests}

The authors declare that they have no competing interests.

\section{Author details}

${ }^{1}$ Department of Medical Diagnostics, Faculty of Allied Health Sciences, Kwame Nkrumah University of Science and Technology, Kumasi, Ghana. ${ }^{2}$ Department of Molecular Medicine, School of Medical Science, Kwame Nkrumah University of Science and Technology (KNUST), Kumasi, Ghana. ${ }^{3}$ School of Medical and Health Sciences, Edith Cowan University, Joondalup, Western Australia, Australia. ${ }^{4}$ Department of Biochemistry, Dalian Medical University, Dalian, China.

Received: 2 May 2019 Accepted: 7 October 2019

Published online: 24 October 2019

\section{References}

1. Economic develpments and outlooks. https://www.worldbank.org/en/ country/ghana/overview. Accessed 17 Apr 2019.

2. Ofori-Asenso R, Agyeman AA, Laar A, Boateng D. Overweight and obesity epidemic in Ghana-a systematic review and meta-analysis. BMC Public Health. 2016;16(1):1239.

3. Frempong RB, Annim SK. Dietary diversity and child malnutrition in Ghana. Heliyon. 2017;3(5):e00298.

4. Darfour B, Rosentrater KA. Maize in Ghana: an overview of cultivation to processing. In: 2016 ASABE Annual International Meeting: 2016: American Society of Agricultural and Biological Engineers; 2016. p. 1.

5. Obesity and overweight. https://www.who.int/news-room/fact-sheets/detail/ obesity-and-overweight. Accessed 21 Mar 2019.

6. Muthuri SK, Francis CE, Wachira L-JM, LeBlanc AG, Sampson M, Onywera VO, Tremblay MS. Evidence of an overweight/obesity transition among schoolaged children and youth in sub-Saharan Africa: a systematic review. PLoS One. 2014;9(3):e92846.

7. Peltzer K, Pengpid S. Overweight and obesity and associated factors among school-aged adolescents in Ghana and Uganda. Int J Environ Res Public Health. 2011;8(10):3859-70.

8. Mogre V, Gaa PK, Abukari RNS. Overweight, obesity and thinness and associated factors among school-aged children (5-14 years) in tamale, Northern Ghana. Eur Sci J. 2013;9:20,

9. Langendijk G, Wellings S, van Wyk M, Thompson SJ, McComb J, Chusilp K. The prevalence of childhood obesity in primary school children in urban Khon Kaen, northeast Thailand. Asia Pac J Clin Nutr. 2003;12:1.

10. Assembly BM. In: Secretariate M, editor. Annual composite Progress reports in; 2014.

11. Ghana Statistical Service G. District Analytical Report. In: Affairs MoF, editor. : Canada: International Development Cooperation; 2014. p. 1-84.

12. Aryeetey R, Lartey A, Marquis GS, Nti H, Colecraft E, Brown P. Prevalence and predictors of overweight and obesity among school-aged children in urban Ghana. BMC obesity. 2017:4(1):38. 
13. Amidu N, Owiredu W, Saaka M, Quaye L, Wanwan M, Kumibea P, Zingina F, Mogre V. Determinants of childhood obesity among basic school children aged 6-12 years in tamale Metropolis. J Med Biomed Sci. 2013;2(3):26-34.

14. Ogden C, Carroll MD, Curtin LR, Lamb MM, Flegal KM. About childhood obesity. JAMA. 2010;303(3):242-9.

15. Manyanga T, El-Sayed H, Doku DT, Randall JR. The prevalence of underweight, overweight, obesity and associated risk factors among school-going adolescents in seven African countries. BMC Public Health. 2014;14(1):887.

16. Kumah D, Akuffo K, Abaka-Cann J, Affram D, Osae E. Prevalence of overweight and obesity among students in the Kumasi metropolis. J Nutr Metabol. 2015;2015:613207.

17. Toriola AL, Moselakgomo V, Shaw B, Goon DT. Overweight, obesity and underweight in rural black south African children. South Afr J Clin Nutr. 2012:25(2):57-61.

18. Zhang J, Yi Z, Feng XQ, Li WR, Lyu YB, Astell-Burt T, Zhao PY, Shi XM. Gender differences in the prevalence of overweight and obesity, associated behaviors, and weight-related perceptions in a national survey of primary school children in China. Biomed Environ Sci. 2018;31(1):1-11.

19. Mushtaq MU, Gull S, Mushtaq K, Shahid U, Shad MA, Akram J. Dietary behaviors, physical activity and sedentary lifestyle associated with overweight and obesity, and their socio-demographic correlates, among Pakistani primary school children. Int J Behav Nutr Phys Act. 2011;8(1):130.

20. Berkey CS, Rockett HR, Field AE, Gillman MW, Frazier AL, Camargo CA, Colditz GA. Activity, dietary intake, and weight changes in a longitudinal study of preadolescent and adolescent boys and girls. Pediatrics. 2000; 105(4):e56.

21. Nuru H, Mamang F. Association between snacking and obesity in children: a review. Int J Commun Med Public Health. 2017;2(3):196-200.

22. Nisak AJ, Qonita Rachmah, and TM, Segalita C. Snacking energy-dense food related to childhood obesity. J Nutr Food Sci 2018, 8(5):1-5.

23. Amigo Vázquez I, Peña Suárez E, Errasti Pérez JM, Busto Zapico R. Sedentary versus active leisure activities and their relationship with sleeping habits and body mass index in children of 9 and 10 years of age. J Health Psychol. 2016;21(7).

24. Ghavamzadeh S, Khalkhali HR, Alizadeh M. TV viewing, independent of physical activity and obesogenic foods, increases overweight and obesity in adolescents. J Health Popul Nutr. 2013;31(3):334.

25. Zimmerman FJ, Bell JF. Associations of television content type and obesity in children. Am J Public Health. 2010;100(2):334-40.

26. Planinšec J, Matejek Č. Differences in physical activity between nonoverweight, overweight and obese children. Coll Antropol. 2004;28(2): 747-54.

27. Leproult R, Van Cauter E. Role of sleep and sleep loss in hormonal release and metabolism. In: Pediatric Neuroendocrinology. Volume 17, edn: Karger Publishers; 2010. p. 11-21.

28. Hart CN, Carskadon MA, Considine RV, Fava JL, Lawton J, Raynor HA, Wing R. Changes in children's sleep duration on food intake, weight, and leptin. Pediatrics. 2013;132(6):e1473-80.

\section{Publisher's Note}

Springer Nature remains neutral with regard to jurisdictional claims in published maps and institutional affiliations.

Ready to submit your research? Choose BMC and benefit from:

- fast, convenient online submission

- thorough peer review by experienced researchers in your field

- rapid publication on acceptance

- support for research data, including large and complex data types

- gold Open Access which fosters wider collaboration and increased citations

- maximum visibility for your research: over $100 \mathrm{M}$ website views per year

At $\mathrm{BMC}$, research is always in progress.

Learn more biomedcentral.com/submissions 